\title{
Patients affected by squamous cell carcinoma of the head and neck: A population particularly prone to developing severe forms of COVID-19
}

\author{
FRANCESCO PERRI $^{1}$, ANNA CRISPO ${ }^{2}$, FRANCO IONNA ${ }^{3}$, PAOLO MUTO ${ }^{4}$, FRANCESCO CAPONIGRO $^{1}$, \\ FRANCESCO LONGO ${ }^{5}$, CONCETTA MONTAGNESE ${ }^{2}$, PIERLUIGI FRANCO ${ }^{3}$, ETTORE PAVONE ${ }^{3}$, \\ CORRADO AVERSA $^{3}$, AGOSTINO GUIDA ${ }^{3}$, SABRINA BIMONTE ${ }^{6}$, ALESSANDRO OTTAIANO ${ }^{7}$, \\ MASSIMILIANO DI MARZO ${ }^{8}$, GIUSEPPE PORCIELLO ${ }^{2}$, ALFONSO AMORE $^{9}$, EGIDIO CELENTANO ${ }^{2}$, \\ GIUSEPPINA DELLA VITTORIA SCARPATI ${ }^{10}$ and MARCO CASCELLA ${ }^{6}$
}

\footnotetext{
${ }^{1}$ Head and Neck Medical and Experimental Oncology Unit; ${ }^{2}$ Epidemiology and Biostatistics Unit; ${ }^{3}$ Otolaryngology Unit;

${ }^{4}$ Radiation Oncology Unit, Istituto Nazionale Tumori, IRCCS ‘Fondazione G. Pascale', I-80131 Naples;

${ }^{5}$ Otolaryngology Unit, Casa Sollievo della Sofferenza di San Giovanni Rotondo, I-71013 Foggia;

${ }^{6}$ Department of Anesthesia and Pain Medicine; ${ }^{7}$ Innovative Therapies for Abdominal Metastases, Department of

Abdominal Oncology; ${ }^{8}$ Colorectal and Abdominal Surgery Unit; ${ }^{9}$ Department Melanoma, Soft Tissue,

Muscle-Skeletal and Head-Neck, Istituto Nazionale Tumori, IRCCS 'Fondazione G. Pascale', I-80131 Naples;

${ }^{10}$ Medical Oncology Unit, San Rocco Hospital, Sessa Aurunca, I-81037 Caserta, Italy
}

Received August 12, 2020; Accepted February 17, 2021

DOI: $10.3892 / \mathrm{etm} .2021 .10733$

\begin{abstract}
Severe acute respiratory syndrome coronavirus 2 (SARS-CoV-2) is responsible for the recent Coronavirus Disease 2019 (COVID-19) pandemic, which has spread all over the world over the past year. Comorbidities appear to affect the prognosis of patients with such diseases, but the impact of cancer on the course of SARS-CoV2 has remained largely elusive. The aim of the present study is to analyze the outcome of patients affected by squamous cell carcinoma of the head and neck (SCCHN) and a number of their comorbidities, if infected with SARS-CoV2. The clinical data of 100 patients affected by SCCHN, who were undergoing treatment or who had finished their oncologic treatment in the past 6 months, were retrospectively collected and analysed. For each patient, the Charlson Comorbidity Index (CCI) was calculated to provide a score assessing the real weight of comorbidities on the patient's outcome at the time of diagnosis. It was discovered that these patients, besides the SCCHN, frequently presented at diagnosis with several other comorbidities, including hypertension, type 2 diabetes, cardiac arrhytmia,
\end{abstract}

Correspondence to: Dr Francesco Perri, Head and Neck Medical and Experimental Oncology Unit, Istituto Nazionale Tumori, IRCCS 'Fondazione G. Pascale', 8031 Via M. Semmola, I-80131 Naples, Italy

E-mail: f.perri@istitutotumori.na.it

Key words: COVID-19, SARS-COV-2, cancer, squamous cell carcinoma of the head and neck, Charlson comorbidity index chronic obstructive pulmonary disease and various forms of vasculopathy (and thus a poor CCI). This feature suggest that, given the high frequency of various comorbidities in patients with SCCHN, additional SARS-CoV2 infection could have particularly devastating consequences.

\section{Introduction}

Recently, severe acute respiratory syndrome coronavirus 2 (SARS-CoV-2) infection has spread worldwide, causing the Coronavirus Disease 2019 (COVID-19) pandemic. The causative pathogen SARS-CoV-2 belongs to the big family of the coronaviruses (CoVs). Human CoVs normally cause respiratory, gastrointestinal and neurologic diseases; outcomes may vary from mild self-limiting disease to more severe manifestations until death $(1,2)$. Humans may be infected by seven types of CoVs, four of which provoke mild self-limiting upper respiratory disease, while the other three CoVs may cause fatal respiratory diseases. In particular, SARS-CoV and Middle-East Respiratory-Syndrome-Coronavirus caused two epidemics in 2002 and in 2012, respectively. SARS-CoV-2 has generated the most recent pandemic, which started in December 2019 in the city of Wuhan in China $(3,4)$. Due to high contagiousness, SARS-CoV-2 has rapidly spread beyond the borders of China, now affecting the entire Globe.

The clinical spectrum of COVID-19 is wide, comprising asymptomatic infection, mild upper respiratory tract disease and in certain cases severe viral pneumonia with respiratory failure that may be fatal. Common symptoms are fever and cough, followed by sputum production, fatigue, musculoskeletal diffuse pain, diarrhea and headache. Cases that progress to severe pneumonitis are characterized by dyspnea, cyanosis 
and fever, fitting the clinical framework of acute respiratory distress syndrome (5-7). If this scenario occurs, comorbidities have been reported to have a strong impact on prognosis (8). However, due to the sparsity of data available, information on the outcome of the disease in patients affected by cancer has remained limited. Data emerging from the few published papers examining the association with COVID-19 highlights the heavy impact of cancer on prognosis $(9,10)$. It may thus be presumed that COVID-19 tends to have a poor outcome in cancer patients.

The Charlson comorbidity index (CCI) has been developed and validated as a measure of the 10-year mortality risk and disease burden (11). This index has been extensively used in clinical research to address the confounding influence of comorbidities, predict outcomes, to standardize and for self-reporting of comorbidities (12-14). In cancer patients, radiation therapy does not appear to affect the CCI, but patients may develop late toxicity (pharynx fibrosis, permanent xerostomia, dysphagia and malnutrition), which increases the probability to develop other comorbidities.

In clinical practice, the CCI may be used as a single numeric score reflecting comorbidities that may assist health care professionals in stratifying patients into subgroups based on disease severity, and developing, in turn, targeted models of care $(12,15)$.

In the present study, data on a cohort of cancer patients affected by squamous cell carcinoma of the head and neck (SCCHN) were collected and analysed. The CCI was calculated for each patient. Based on the thereby obtained data (CCI is an index of the global comorbidity status of these patients) and based on a rigorous analysis of the pathogenesis of both SCCHN and COVID-19, the ultimate aim of this study is to assess the relationship between SARS-CoV-2 infection and the outcome in patients with SCCHN.

\section{Patients and methods}

Patients and outcome. Starting from the 31th of March 2020, clinical data of a group of consecutive patients affected by SCCHN with ongoing/completed anticancer therapy presenting at the outpatient clinic of the Head and Neck Medical and Experimental Oncology Unit of the National Cancer Institute (Naples, Italy) were retrospectively collected. Patients who had finished chemotherapy $>6$ months previously were excluded. Data regarding age at diagnosis, type of oncologic treatment, stage of disease, number and type of comorbidities at diagnosis, smoking status and site of insurgence of the tumour were collected. Sampling stopped at 100 patients. The CCI for each individual was calculated to obtain an extra score assessing the real weight of comorbidities on the outcome of patients at the time-point of diagnosis. Each patient was assigned a score ranging from 0 to 10 , according to the guidelines currently used for the calculation of the CCI (14). A score of 5 means that the 10 -year overall survival is $\sim 21 \%$, independently from the therapy performed, while a score $\geq 7$ translates into a 10 -year survival of $0 \%$ (10). This CCI scoring system was previously used on patients with tumors of the gastrointestinal tract, but the results can be extended to all other malignancies $(16,17)$.

Statistical analysis. Data are reported in frequency tables with numbers and percentages. Comparisons among patients stratified by the $\mathrm{CCI}(<5$ and $\geq 5)$ and various features were made by using Chi-square tests for categorical variables. Fisher's exact test was used when the Chi-square test was not applicable ( $>20 \%$ of cells have expected $n$ values $\leq 5$ ). Multivariate logistic regression was used to determine the probability of $\mathrm{CCI} \geq 5$ as the outcome in relation to patient characteristics and comorbidities. Odds ratio (ORs) and corresponding confidence intervals (CI) were computed by multivariate logistic regression models adjusted for age, sex and other potential confounding factors to assess risk. SPSS software version 26.0 (IBM Corp.) was used to perform all analyses. $\mathrm{P}<0.05$ was considered to indicate statistical significance.

\section{Results}

Baseline data. Data regarding 100 patients affected by SCCHN were collected, 52 of which were in treatment and 48 had completed therapy. The patients' data are summarised in Table I. A total of 66 patients were male and 34 female and the median age was 62 years (range, 27-83 years; mean age, $61.1 \pm 10.9$ years). Of these, $73 \%$ had loco-regional disease, while 27 had advanced disease (recurrent/metastatic) and the oral cavity was the most frequent site of onset of cancer. A total of 78 patients were smokers (light or strong smokers). Furthermore, 86 patients had at least one comorbidity (Table II) and 33 of them had 3 or more comorbidities. The most frequent comorbidity was hypertension, which was present in 62 patients, followed by chronic obstructive pulmonary disease (COPD, $n=30)$ and diabetes (15).

CCI analysis. A total of 32 patients had a CCI score $\geq 7$ (10-year survival rate, $0.0 \%$ ). The median CCI value was 5 (range, 2-10; 10-year survival rate, $21.3 \%)(10)$.

Based on the median CCI value, the patients were divided into two groups, namely those with $\mathrm{CCI}<5$ and those with $\mathrm{CCI} \geq 5$.

Table III presents the distribution of CCI according to major variables. The results indicated that older age, the primary location of the tumor, heavy smoking and a higher number of comorbidities were significantly related to a higher CCI ( $\mathrm{P}<0.001,0.017,0.023$ and $<0.001$, respectively).

Table IV indicates the distribution of comorbidities in certain categories. The results suggested that certain categories of comorbidities, namely the respiratory and cardiovascular ones, were more common in the $\mathrm{CCI} \geq 5$ group (CCI $\geq 5$ vs. $\mathrm{CCI}<5,43.9 \%$ vs. $11.6 \%, \mathrm{P}<0.0001 ; \mathrm{CCI} \geq 5$ vs. $\mathrm{CCI}<5,75.4 \%$ vs. $55.8 \%$; $\mathrm{P}=0.04)$.

The results of the adjusted multivariate logistic regression indicated that the type of cancer, older age, smoking status and respiratory disease were significant risk factors for a high CCI (Table V). A primary tumour site in the oral cavity was significantly associated with $\geq 5 \mathrm{CCI}(\mathrm{OR}=3.86,95 \%$ CI: $1.35-11.0)$, and so was an age of $\geq 60$ years ( $\mathrm{OR}=8.13,95 \%$ CI: $2.88-22.9$ ), heavy smoking (OR=4.13, 95\% CI: 1.06-16.03) and COPD I/II $(\mathrm{OR}=6.67,95 \%$ CI: $1.82-24.43)$.

\section{Discussion}

SCCHN is a heterogeneous disease arising from the first tract of the aero-digestive ways and it accounts for 7-8\% of 
Table I. Main features of 100 cases of head and neck cancer.

\begin{tabular}{|c|c|}
\hline Feature & $\mathrm{N}$ \\
\hline \multicolumn{2}{|l|}{ Sex } \\
\hline Male & 66 \\
\hline Female & 34 \\
\hline \multicolumn{2}{|l|}{ Age (years) } \\
\hline Mean \pm SD & $61.1 \pm 10.9$ \\
\hline$\leq 50$ & 18 \\
\hline $51-60$ & 27 \\
\hline $61-70$ & 36 \\
\hline$>70$ & 19 \\
\hline \multicolumn{2}{|l|}{ Type of cancer } \\
\hline Oral cavity $\mathrm{C}$ & 39 \\
\hline Oropharyngeal C & 21 \\
\hline Nasopharyngeal C & 13 \\
\hline Larynx C & 14 \\
\hline Hypopharyngeal C & 6 \\
\hline Paranasal sinuses $\mathrm{C}$ & 6 \\
\hline Parotid C & 1 \\
\hline \multicolumn{2}{|l|}{ Stage } \\
\hline Early & 2 \\
\hline Locally advanced & 71 \\
\hline Recurrent/metastatic & 27 \\
\hline \multicolumn{2}{|l|}{ Smoking status } \\
\hline Non-smoker & 22 \\
\hline Smoker-light ( $\leq 20 /$ day) & 33 \\
\hline Smoker-strong (>20/day) & 45 \\
\hline \multicolumn{2}{|l|}{ Comorbidities (n) } \\
\hline 0 & 14 \\
\hline $1-2$ & 53 \\
\hline$\geq 3$ & 33 \\
\hline \multicolumn{2}{|l|}{ CCI } \\
\hline Median (range) & $5(2-10)$ \\
\hline $1-6$ & 68 \\
\hline$\geq 7$ & 32 \\
\hline
\end{tabular}

C, carcinoma; CCI, Charlson Comorbidity Index; SD, standard deviation.

all malignancies (18). Studies on the pathogenesis of SCCHN have revealed that the host's inflammatory response has an important role in tumour development and progression, and the clinical condition of numerous patients is frequently characterized by an imposing chronic inflammation, particularly in the more advanced stages of the disease $(19,20)$. This chronic inflammatory status has been reported to be associated with both tumour burden and poor prognosis (19-22). As this came to our attention in clinical practice, the aim of the present study was to determine whether patients affected by SCCHN may potentially have a higher risk of developing severe COVID-19, and the pathogenesis of both diseases was considered. In SCCHN, as well as in other types of solid tumour, the serum concentration of certain pro-inflammatory
Table II. Frequency of comorbidities in 100 cases of head and neck cancer.

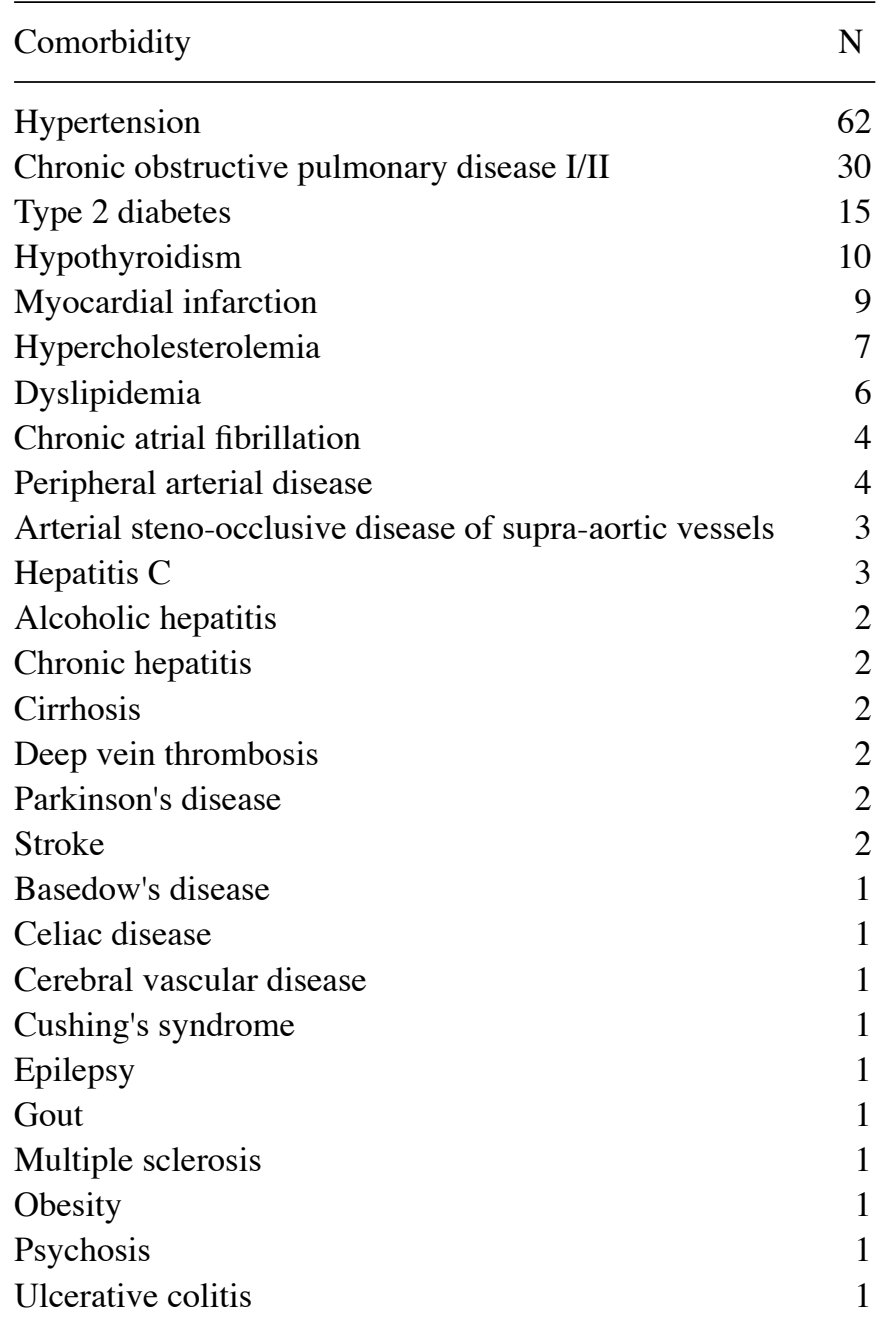

cytokines is high and one of them, interleukin (IL)-6, has been reported to be almost always upregulated and to be linked to resistance to anticancer therapies (23-25). IL-6 is produced by several cell types, including tumour cells, that has been indicated to be involved in normal cell inflammatory processes, in host immune defence mechanisms and in the modulation of cellular growth (24). IL-6 is able to easily cross the blood-brain barrier, inducing the synthesis of prostaglandin E2 in the hypothalamus and thereby changing the body's temperature set point. IL-6 is able to stimulate the acute phase of protein synthesis and it also increases the production of neutrophils in the bone marrow (26). IL-6 is able to regulate $\mathrm{B}$-lymphocyte and $\mathrm{T}$ regulatory lymphocyte function, but most importantly, IL-6 is involved in the proliferation and differentiation of various malignant tumour cell types. In fact, by interacting with its receptor, IL-6 activates the Janus kinase pathway, which results in the activation of signal transducer and activator of transcription 3 (STAT3) to form phosphorylated (p)STAT3. The engagement of pSTAT3 dimers then initiates a change in the transcription of a number of genes, including the apoptotic regulatory genes Bcl-XL, X-linked inhibitor of apoptosis protein and Fas and in addition, pSTAT3 binds to p53 and inhibits its 
Table III. Distribution of cases of head \& neck cancer $(n=100)$ with a high or low Charlson Comorbidity Index (CCI) according to selected variables.

\begin{tabular}{|c|c|c|c|}
\hline \multirow[b]{2}{*}{ Item } & \multicolumn{2}{|c|}{$\mathrm{CCI}$} & \multirow[b]{2}{*}{ P-value } \\
\hline & $<5$ & $\geq 5$ & \\
\hline Sex & & & 0.310 \\
\hline Male & $26(60.5)$ & $40(70.2)$ & \\
\hline Female & $17(39.5)$ & $17(29.8)$ & \\
\hline Age (years) & & & $<0.001$ \\
\hline$<60$ & $27(62.8)$ & $11(19.3)$ & \\
\hline$\geq 60$ & $16(37.2)$ & $46(80.7)$ & \\
\hline Location of cancer & & & 0.017 \\
\hline Oral cavity & $11(25.6)$ & $28(49.1)$ & \\
\hline All others & $32(74.4)$ & $29(49.1)$ & \\
\hline Stage & & & $<0.001$ \\
\hline Early/locally advanced & $41(95.3)$ & $32(56.1)$ & \\
\hline Recurrent/metastatic & $2(4.7)$ & $25(43.9)$ & \\
\hline Smoking status & & & 0.023 \\
\hline Non-smoker & $15(34.9)$ & $7(12.3)$ & \\
\hline Smoker-light ( $\leq 20 /$ day) & $13(30.2)$ & $20(35.1)$ & \\
\hline Smoker-strong ( $>20 /$ day) & $15(34.9)$ & $30(52.6)$ & \\
\hline Comorbidities (n) & & & $<0.001$ \\
\hline 0 & $13(30.2)$ & $1(1.8)$ & \\
\hline $1-2$ & $23(53.5)$ & $30(52.6)$ & \\
\hline$\geq 3$ & $7(16.3)$ & $26(45.6)$ & \\
\hline
\end{tabular}

P-value was determined using the Chi-square test. CCI, Charlson Comorbidity Index.

function as a regulator of apoptosis, thus promoting tumour cell survival (27-29). Furthermore, IL-6 acts on the immune system by promoting the immunosuppressive status, which initially affects the tumour microenvironment exclusively and subsequently the whole organism. In fact, IL-6 is not only able to stimulate the expression of programmed death ligand 1 on the cell membrane of tumour cells, promoting its capability to circumvent $\mathrm{T}$ cell-mediated tumour killing, but also to stimulate the growth of the myeloid-derived suppressor cells, which are a particular type of immune cells able to suppress the T-cytotoxic lymphocytes, thereby affecting the anti-tumour immune response $(23,30,31)$.

Of note, IL- 6 also has a crucial role in the pathogenesis of severe pulmonary inflammation due to SARS-CoV-2 infection $(32,33)$. Highly pathogenic human $\mathrm{CoVs}$, including SARS-CoV-2, frequently induce massive cell death and cytopathy. Cell death causes extensive inflammation, which in turn drives at least in part the high pathogenicity of this novel CoV. The cell death induced by SARS-CoV-2 is named pyroptosis, which results in the so-called 'pro-inflammatory cytokine storm'. The upregulation of inflammatory cytokines, including IL-1 $\beta$ and IL-6, was observed in SARS-CoV-2-infected monocyte-derived human dendritic cells and tissue models $(34,35)$. Overall,
SARS-CoV-2 leads to the massive synthesis of IL-1 $\beta$, which in turn, further promotes the expression of other pro-inflammatory cytokines such as tumour necrosis factor $\alpha$ and IL-6 $(36,37)$.

On this basis, despite being different pathologies, both HNSCC and COVID-19 share an important part of their pathogenesis, as they share the induction of the "cytokine storm' with IL- 6 being the main cytokine produced.

Another feature shared by both cancer and SARS-CoV-2 infection is the thrombotic diathesis typical of both diseases. Cancer cells are in fact capable of producing the 'cancer pro-coagulant', which is a cysteine proteinase that was discovered for the first time both in malignant cells and in fetal human amnion-chorion tissues (38). Furthermore, cancer patients frequently experience a state of hypercoagulability due to other and different factors, such as surgery, lodging, chemotherapy and hormone therapy. A similar characteristic is common to patients suffering from severe COVID-19-induced pneumonitis, who in the late phase of the disease frequently experience intravascular coagulopathy $(39,40)$. Different causes have been brought up to explain this feature and the most accredited appears to be the induction of anti-phospholipid antibodies (41).

In addition to what has been said, patients affected by SCCHN frequently present with several co-pathologies, which in part may be due to a habit of frequent smoking (42). In fact, COPD of varying severity, as well as heart diseases, usually belong to the clinical picture of patients with SCCHN and their pathogenesis is strongly related to tobacco consumption. These observations are also in line with the present results.

Tobacco smoking may be able to impact the pathogenesis of COVID-19 'per se', since it has been indicated that tobacco use significantly increases the gene expression of angiotensin-converting enzyme 2 , the binding receptor for SARS-CoV-2, which also explains the elevated susceptibility of smokers to COVID-19 (43). Cigarette smoking is the leading cause of COPD, which has been identified as an independent risk factor of severe COVID-19 $(44,45)$. In the present study, $78 \%$ of the patients had a smoking habit.

The main conclusion is that SCCHN and COVID-19 support each other by self-empowering each other. Another possible conclusion is that patients affected by SCCHN have a poor comorbidity status and a poor prognosis already at diagnosis and thus, they are characterized by a particular clinical fragility that may make them vulnerable to COVID-19. This last feature is well highlighted by the poor median CCI value of 5 obtained following descriptive analysis. However, the main limitation of this analysis, apart for its retrospectivity, is the lack of a control group in which patients with a poor CCI but not affected by SCCHN are present.

The COVID-19 pandemic is a public health emergency of international concern. Several vaccines against COVID-19 have been developed and a global vaccination campaign has been underway in recent months (46). The strategies used to treat patients with severe SARS-CoV2 have been particularly improved and now involve the use of multiple drugs, including corticosteroids, heparin and cytokine antagonists (47-49). However, in each case, special attention should be paid to 
Table IV. Distribution of cases of head \& neck cancer $(n=100)$ with a high or low CCI according to and main groups of comorbidities.

\begin{tabular}{|c|c|c|c|}
\hline \multirow[b]{2}{*}{ Comorbidity } & \multicolumn{2}{|c|}{$\mathrm{CCI}$} & \multirow[b]{2}{*}{ P-value } \\
\hline & $<5$ & $\geq 5$ & \\
\hline Hypertension & & & $0.052^{\mathrm{a}}$ \\
\hline No & $21(48.8)$ & $17(29.8)$ & \\
\hline Yes & $22(21.2)$ & $40(70.2)$ & \\
\hline Respiratory (COPD I/II) & & & $<0.001^{\mathrm{a}}$ \\
\hline No & $38(88.4)$ & $32(56.1)$ & \\
\hline Yes & $5(11.6)$ & $25(43.9)$ & \\
\hline Cardiovascular diseases & & & $0.039^{\mathrm{a}}$ \\
\hline No & $19(44.2)$ & $14(24.6)$ & \\
\hline Yes & $24(55.8)$ & $43(75.4)$ & \\
\hline Endocrine and metabolic disorders & & & $0.103^{\mathrm{a}}$ \\
\hline No & $33(76.7)$ & $35(61.4)$ & \\
\hline Yes & $10(23.3)$ & $22(38.6)$ & \\
\hline Type 2 diabetes & & & $0.012^{\mathrm{b}}$ \\
\hline No & $41(95.3)$ & $44(77.2)$ & \\
\hline Yes & $2(4.7)$ & $13(22.8)$ & \\
\hline Liver diseases & & & $0.257^{\mathrm{b}}$ \\
\hline No & $43(100)$ & $54(94.7)$ & \\
\hline Yes & 0 & $3(5.3)$ & \\
\hline Nervous system diseases & & & $0.234^{\mathrm{b}}$ \\
\hline No & $42(97.7)$ & $51(89.5)$ & \\
\hline Yes & $1(2.3)$ & $6(10.5)$ & \\
\hline Autoimmune diseases & & & $>0.999^{b}$ \\
\hline No & $42(97.7)$ & $55(96.5)$ & \\
\hline Yes & $1(2.3)$ & $2(3.5)$ & \\
\hline
\end{tabular}

${ }^{a}$ Chi-squared test. ${ }^{b}$ Fisher's exact test. Cardiovascular diseases: Hypertension, deep vein thrombosis, stroke, chronic atrial fibrillation, myocardial infarction, cerebral vasculitis, arteriopathy, peripheral arterial disease; Endocrine and metabolic disorders: Obesity, dyslipidemia, hypothyroidism, gout, hypercortisolism; Respiratory group: COPD I/II; Liver diseases: Alcoholic hepatitis, chronic hepatitis, cirrhosis, Hepatitis C virus; Nervous system diseases: Parkinson's disease, epilepsy, psychosis; Autoimmune diseases: Celiac diseases, multiple sclerosis, ulcerative colitis, Basedow disease. CCI, Charlson comorbidity index; COPD, chronic obstructive pulmonary disease.

Table V. Summary of logistic regression analysis for the probability of an outcome of Charlson Comorbidity Index $\geq 5$.

\begin{tabular}{|c|c|c|c|c|}
\hline \multirow{2}{*}{$\begin{array}{l}\text { Parameter } \\
\text { Item }\end{array}$} & \multicolumn{2}{|c|}{ Univariate logistic regression } & \multicolumn{2}{|c|}{ Multivariate logistic regression } \\
\hline & OR $(95 \% \mathrm{CI})$ & P-value & OR $(95 \% \mathrm{CI})$ & P-value \\
\hline Oral cavity carcinoma & $3.86(1.35-11.0)$ & 0.015 & $2.81(1.19-6.63)$ & 0.019 \\
\hline Age $\geq 60$ years & $8.13(2.88-22.9)$ & $<0.001$ & $7.06(2.86-17.41)$ & $<0.001$ \\
\hline Smoking (light) & $1.68(0.45-6.32)$ & 0.423 & $3.30(1.06-10.28)$ & 0.040 \\
\hline Smoking (heavy) & $4.13(1.06-16.03)$ & 0.041 & $4.29(1.44-12.75)$ & 0.009 \\
\hline Hypertension & $0.98(0.35-2.72)$ & 0.962 & $2.25(0.99-5.12)$ & 0.054 \\
\hline Respiratory group (COPD I/II) & $6.67(1.82-24.43)$ & 0.004 & $5.94(2.04-17.30)$ & 0.001 \\
\hline Cardiovascular Diseases & $1.05(0.37-2.98)$ & 0.081 & $2.43(1.04-5.70)$ & 0.041 \\
\hline Endocrine and Metabolic Disorders & $1.39(0.47-4.12)$ & 0.567 & $2.07(0.86-5.03)$ & 0.107 \\
\hline
\end{tabular}

The odds ratio was adjusted for sex, age, smoking status and type of cancer. COPD, chronic obstructive pulmonary disease. 
the more vulnerable populations to contain and manage this infection.

Patients with certain types of cancer often have various comorbidities, making them vulnerable (50). Patients affected by lung cancer and/or SCCHN, for example, typically have a long history of smoking and, in the case of SCCHN, heavy drinkers; both of which associated with pulmonary, liver and cardiac diseases $(18,51)$. The present analysis highlighted that patients affected by SCCHN are a particularly susceptible population, since they frequently have several comorbidities at diagnosis. Since the outcome of COVID-19 is strongly influenced by underlying pathologies, including respiratory and cardiovascular diseases, it may be speculated that a SARS-CoV-2 infection may have detrimental effects in patients with SCCHN.

The most frequent demographic of SCCHN study is the male sex in the $>60$ years age group, with tumour of the oral cavity, heavy smoker and at $\geq 2$ comorbidities, including COPD of varying severity. Given these features, it could be speculated that such patient could develop a severe form of the disease if affected by COVID-19.

\section{Acknowledgements}

The authors thank Dr Alessandra Trocino from the Library Unit of Istituto Nazionale Tumori, IRCCS 'Fondazione G. Pascale' (Naples, Italy) for the references collected.

\section{Funding}

No funding received.

\section{Availability of data and materials}

The datasets used and/or analyzed during the present study are available from the corresponding author on reasonable request.

\section{Authors' contributions}

Conception and design: FP, AC, FI, PM, GDVS, MC; acquisition of data, and analysis and interpretation of data: FP, AC, FI, PM, FC, FL, CM, PF, EP, CA, AG, SB, AO, MD, GP, AA, EC, GDVS, MC; literature analysis (bibliographic research): AG, $\mathrm{SB}, \mathrm{AO}, \mathrm{MD}, \mathrm{GP}, \mathrm{AA}, \mathrm{EC}, \mathrm{GDV}, \mathrm{MC}$; searching the literature: FP, AC, FI, PM, FC, FL, CM, PF, EP, CA, AG, SB, AO, MD, GP, AA, EC, GDVS, MC; drafting the manuscript : FP, GDVS, MC; statistical analysis: FP, AC, CM; editing: FP, AC, MC, AG. FP, GDVS and MC conceived the work and they conceived the design of the work and they checked and approved the authenticity of the raw data. FP, AC, FI, PM, FC, FL, CM, PF, EP, CA, AG, SB, AO, MD, GP, AA, EC, GDVS, MC revised critically the work for important intellectual content. All authors read and approve the final manuscript.

\section{Ethics approval and consent to participate}

All patients provided written informed consent and no ethical committee approval was necessary according to our ethical institution rules for the type of study as it was an observational/retrospective study.

\section{Patient consent for publication}

Not applicable.

\section{Competing interests}

The authors declare that they have no competing interests.

\section{References}

1. Yu F, Du L, Ojcius DM, Pan C and Jiang S: Measures for diagnosing and treating infections by a novel coronavirus responsible for a pneumonia outbreak originating in Wuhan, China. Microbes Infect 22: 74-79, 2020.

2. Chan KH, Chan JF, Tse H, Chen H, Lau CC, Cai JP, Tsang AK, Xiao X, To KK, Lau SK, et al: Cross-reactive antibodies in convalescent SARS patients' sera against the emerging novel human coronavirus EMC (2012) by both immunofluorescent and neutralizing antibody tests. J Infect 67: 130-140, 2013.

3. Perlman S: Another decade, another coronavirus. N Engl J Med 382: 760-762, 2020.

4. General Office of National Health Committee. Office of State Administration of Traditional Chinese Medicine. Notice on the issuance of a programme for the diagnosis and treatment of novel coronavirus (2019-nCoV) infected pneumonia (Trial Version 4).; 2020. Available from: http://bgs.satcm.gov.cn/

5. Du Y, Tu L, Zhu P, Mu M, Wang R, Yang P, Wang X, Hu C, Ping R, Hu P, et al: Clinical features of 85 fatal cases of COVID-19 from Wuhan. A retrospective observational study. Am J Respir Crit Care Med 201: 1372-1379, 2020.

6. Wang Z, Yang B, Li Q, Wen L and Zhang R: Clinical features of 69 cases with coronavirus disease 2019 in Wuhan, China. Clin Infect Dis 71: 769-777, 2020.

7. Li YK, Peng S, Li LQ, Wang Q, Ping W, Zhang $\mathrm{N}$ and Fu XN: Clinical and transmission characteristics of Covid-19-A retrospective study of 25 cases from a single thoracic surgery department. Curr Med Sci 40: 295-300, 2020.

8. Wang Z, Deng H, Ou C, Liang J, Wang Y, Jiang M and Li S: Clinical symptoms, comorbidities and complications in severe and non-severe patients with COVID-19: A systematic review and meta-analysis without cases duplication. Medicine (Baltimore) 99: e23327, 2020.

9. Jazieh AR, Alenazi TH, Alhejazi A, Al Safi F and Al Olayan A: Outcome of oncology patients infected with coronavirus. JCO Glob Oncol 6: 471-475, 2020.

10. Ye Z, Hong Y, Wu X, Hong D, Zhang Y, Dong X, Rao Y and Lu X: Management of a colon cancer patient complicated with COVID-19. Zhejiang Da Xue Xue Bao Yi Xue Ban 49: 245-248, 2020 (In Chinese).

11. Charlson ME, Pompei P, Ales KL and MacKenzie CR: A new method of classifying prognostic comorbidity in longitudinal studies: Development and validation. J Chronic Dis 40: 373-383, 1987.

12. Charlson ME, Charlson RE, Peterson JC, Marinopoulos SS, Briggs WM and Hollenberg JP: The Charlson comorbidity index is adapted to predict costs of chronic disease in primary care patients. J Clin Epidemiol 61: 1234-1240, 2008.

13. Hall WH, Ramachandran R, Narayan S, Jani AB and Vijayakumar S: An electronic application for rapidly calculating Charlson comorbidity score. BMC Cancer 4: 94, 2004.

14. de Groot V, Beckerman H, Lankhorst GJ and Bouter LM: How to measure comorbidity. a critical review of available methods. J Clin Epidemiol 56: 221-229, 2003.

15. Charlson Comorbidity Index (CCI). Available from: https://www. mdcalc.com/charlson-comorbidity-index-cci.

16. VAN Halteren HK and Vreugdenhil G: Age adjusted charlson comorbidity index strongly influences survival, irrespective of performance status and age, in patients with advanced prostatic cancer treated with enzalutamide. Anticancer Res 39: 863-866, 2019.

17. Zhao L, Leung LH, Wang J, Li H, Che J, Liu L, Yao X and Cao B: Association between Charlson comorbidity index score and outcome in patients with stage IIIB-IV non-small cell lung cancer. BMC Pulm Med 17: 112, 2017.

18. Perri F, Muto P, Aversa C, Daponte A, Della Vittoria G, Pepe S and Caponigro F: Integrated therapeutic approaches in head and neck cancer: The importance of multidisciplinary team management. Anticancer Agents Med Chem 13: 834-843, 2013. 
19. Chen MF, Tsai MS, Chen WC and Chen PT: Predictive value of the pretreatment neutrophil-to-lymphocyte ratio in head and neck squamous cell carcinoma. J Clin Med 7: 294, 2018.

20. Valero C, Pardo L, López M, García J, Camacho M, Quer M and León X: Pretreatment count of peripheral neutrophils, monocytes, and lymphocytes as independent prognostic factor in patients with head and neck cancer. Head Neck 39: 219-226, 2017.

21. Rassouli A, Saliba J, Castano R, Hier M and Zeitouni AG Systemic inflammatory markers as independent prognosticators of head and neck squamous cell carcinoma. Head Neck 37: 103-110, 2015.

22. Wong BY, Stafford ND, Green VL and Greenman J: Prognostic value of the neutrophil-to-lymphocyte ratio in patients with laryngeal squamous cell carcinoma. Head Neck 38 (Suppl 1): E1903-E1908, 2016.

23. Tsai MS, Chen WC, $\mathrm{Lu} \mathrm{CH}$ and Chen MF: The prognosis of head and neck squamous cell carcinoma related to immunosuppressive tumor microenvironment regulated by IL-6 signaling. Oral Oncol 91: 47-55, 2019.

24. Setrerrahmane $\mathrm{S}$ and $\mathrm{Xu} \mathrm{H}$ : Tumor-related interleukins: Old validated targets for new anti-cancer drug development. Mol Cancer 16: 153, 2017.

25. Bharti R, Dey G and Mandal M: Cancer development, chemoresistance, epithelial to mesenchymal transition and stem cells: A snapshot of IL-6 mediated involvement. Cancer Lett 375: 51-61, 2016.

26. Banks WA, Kastin AJ and Gutierrez EG: Penetration of interleukin- 6 across the murine blood-brain barrier. Neurosci Lett 179: 53-56, 1994.

27. Heinrich PC, Behrmann I, Müller-Newen G, Schaper F and Graeve L: Interleukin-6-type cytokine signalling through the gp130/Jak/STAT pathway. Biochem J 334: 297-314, 1998.

28. Lauta VM: A review of the cytokine network in multiple myeloma: Diagnostic, prognostic, and therapeutic implications. Cancer 97: 2440-2452, 2003

29. Scheller J, Ohnesorge N and Rose-John S: Interleukin-6 trans-signalling in chronic inflammation and cancer. Scand J Immunol 63: 321-329, 2006.

30. Yu GT, Bu LL, Huang CF, Zhang WF, Chen WJ, Gutkind JS, Kulkarni AB and Sun ZJ: PD-1 blockade attenuates immunosuppressive myeloid cells due to inhibition of CD47/SIRPo axis in HPV negative head and neck squamous cell carcinoma Oncotarget 6: 42067-42080, 2015.

31. Kitamura H, Ohno Y, Toyoshima Y, Ohtake J, Homma S, Kawamura H, Takahashi N and Taketomi A: Interleukin-6/STAT3 signaling as a promising target to improve the efficacy of cancer immunotherapy. Cancer Sci 108: 1947-1952, 2017.

32. Sanders JM, Monogue ML, Jodlowski TZ and Cutrell JB: Pharmacologic treatments for coronavirus disease 2019 (COVID-19): A review. JAMA 323: 1824-1836, 2020.

33. Nitulescu GM, Paunescu H, Moschos SA, Petrakis D, Nitulescu G, Ion GND, Spandidos DA, Nikolouzakis TK, Drakoulis $\mathrm{N}$ and Tsatsakis A: Comprehensive analysis of drugs to treat SARS-CoV-2 infection: Mechanistic insights into current COVID-19 therapies (Review). Int J Mol Med 46: 467-488, 2020.

34. He L, Ding Y, Zhang Q, Che X, He Y, Shen H, Wang H, Li Z, Zhao L, Geng J, et al: Expression of elevated levels of pro-inflammatory cytokines in SARS-CoV-infected ACE2 ${ }^{+}$cells in SARS patients: Relation to the acute lung injury and pathogenesis of SARS. J Pathol 210: 288-297, 2006.

35. Tang BS, Chan KH, Cheng VC, Woo PC, Lau SK, Lam CC, Chan TL, Wu AK, Hung IF, Leung SY and Yuen KY: Comparative host gene transcription by microarray analysis early after infection of the Huh7 cell line by severe acute respiratory syndrome coronavirus and human coronavirus 229E. J Virol 79: 6180-6193, 2005.

36. Nieto-Torres JL, DeDiego ML, Verdiá-Báguena C, Jimenez-Guardeño JM, Regla-Nava JA, Fernandez-Delgado R, Castaño-Rodriguez C, Alcaraz A, Torres J, Aguilella VM and Enjuanes L: Severe acute respiratory syndrome coronavirus envelope protein ion channel activity promotes virus fitness and pathogenesis. PLoS Pathog 10: e1004077, 2014.
37. DeDiego ML, Nieto-Torres JL, Regla-Nava JA, Jimenez-Guardeño JM, Fernandez-Delgado R, Fett C, Castaño-Rodriguez C, Perlman S and Enjuanes L: Inhibition of NF- $\kappa \mathrm{B}$-mediated inflammation in severe acute respiratory syndrome coronavirus-infected mice increases survival. J Virol 88: 913-924, 2014

38. Gordon SG and Mielicki WP: Cancer procoagulant: A factor X activator, tumor marker and growth factor from malignant tissue. Blood Coagul Fibrinolysis 8: 73-86, 1997.

39. Cui S, Chen S, Li X, Liu S and Wang F: Prevalence of venous thromboembolism in patients with severe novel coronavirus pneumonia. J Thromb Haemost 18: 1421-1424, 2020.

40. Wang J, Hajizadeh N, Moore EE, McIntyre RC, Moore PK, Veress LA, Yaffe MB, Moore HB and Barrett CD: Tissue plasminogen activator (tPA) treatment for COVID-19 associated acute respiratory distress syndrome (ARDS): A case series. J Thromb Haemost 18: 1752-1755, 2020.

41. Zhang Y, Xiao M, Zhang S, Xia P, Cao W, Jiang W, Chen H, Ding $\mathrm{X}$, Zhao $\mathrm{H}$, Zhang $\mathrm{H}$, et al: Coagulopathy and antiphospholipid antibodies in patients with Covid-19. N Engl J Med 382: e38, 2020.

42. Fazel A, Quabius ES, Fabian A, SchleicherT, Kress K, Laudien M, Huber K, Herzog A, Gonzales Donate M and Hoffmann M: The influence of smoking and co-morbidity on dose achievement in primary or adjuvant radio(Chemo)therapy in head and neck squamous cell carcinoma (HNSCC). Front Oncol 10: 398, 2020.

43. Cai G: Bulk and single-cell transcriptomics identify tobacco-use disparity in lung gene expression of ACE2, the receptor of 2019-nCov. Feb 17, 2020. Available from: https://www.medrxiv.org/ content/medrxiv/early/2020/02/17/2020.02.05.20020107.full.pdf

44. Guan WJ, Ni ZY, Hu Y, Liang WH, Ou CQ, He JX, Liu L, Shan H, Lei CL, Hui DSC, et al: Clinical characteristics of coronavirus disease 2019 in China. N Engl J Med 382: 1708-1720, 2020.

45. Jordan SC, Zakowski P, Tran HP, Smith EA, Gaultier C, Marks G, Zabner R, Lowenstein H, Oft J, Bluen B, et al: Compassionate use of tocilizumab for treatment of SARS-CoV-2 pneumonia. Clin Infect Dis 71: 3168-3173, 2020.

46. Green DR: SARS-CoV2 vaccines: Slow is fast. Sci Adv 6 : eabc7428, 2020.

47. Bartoli A, Gabrielli F, Alicandro T, Nascimbeni F and Andreone P: COVID-19 treatment options: A difficult journey between failed attempts and experimental drugs. Intern Emerg Med 1-28, Jan 4, 2021 (Epub ahead of print).

48. Stratton CW, Tang YW and Lu H: Pathogenesis-directed therapy of 2019 novel coronavirus disease. J Med Virol 93: 1320-1342, 2021

49. Hussain A, Hasan A, Nejadi Babadaei MM, Bloukh SH, Chowdhury MEH, Sharifi M, Haghighat S and Falahati M: Targeting SARS-CoV2 spike protein receptor binding domain by therapeutic antibodies. Biomed Pharmacother 130: 110559, 2020.

50. Grünewaldt A, Stützle S, Lehn A and Rohde G: Dyspnoea and comorbidity in lung cancer-patients: The therapy starts with taking the patients history. Pneumologie: Feb 17, 2021 (Epub ahead of print) (In German).

51. Media AS, Persson M, Tajhizi N and Weinreich UM: Chronic obstructive pulmonary disease and comorbidities' influence on mortality in non-small cell lung cancer patients. Acta Oncol 58: 1102-1106, 2019.

This work is licensed under a Creative Commons Attribution-NonCommercial-NoDerivatives 4.0 International (CC BY-NC-ND 4.0) License. 